\title{
Formation of Metal Oxide Nanoparticles in Combustion of Titanium and Aluminum Droplets
}

\author{
V. V. Karasev, ${ }^{1}$ A. A. Onishchuk, ${ }^{1}$ S. A. Khromova, ${ }^{1}$ \\ O. G. Glotov ${ }^{1}$ V. E. Zarko, ${ }^{1}$ E. A. Pilyugina, ${ }^{1}$ and C. J. Tsai ${ }^{2}$ \\ UDC 536.46
}

Translated from Fizika Goreniya i Vzryva, Vol. 42, No. 6, pp. 33-47, November-December, 2006. Original article submitted June 28, 2006.

\begin{abstract}
A study was performed of the formation of metal oxide nanoparticles during combustion of aluminum and titanium drops which moved in air at a velocity of up to $3 \mathrm{~m} / \mathrm{sec}$. The source of the burning particles was a pyrotechnic mixture which contained an oxidizer, a binder, and metal particles of size 4-350 $\mu \mathrm{m}$. Transmission electron microscopic studies showed that the combustion products were 1-10 $\mu \mathrm{m}$ aggregates of fractal structure consisting of primary particles (spherules) of $\mathrm{Al}_{2} \mathrm{O}_{3} / \mathrm{TiO}_{2} \mathbf{5}-150 \mathbf{~ n m}$ in diameter. The Brownian diffusion of the aggregates and their motion in electric and gravitational fields were observed using videomicroscopic recording. The charge distribution of $\mathrm{TiO}_{2}$ aggregates and the equivalent radius of Brownian mobility were determined. In $\mathrm{Al}$ combustion, the zone of nanoparticle formation is separated from the particle surface by a distance approximately equal to the particle radius, and in Ti combustion, this zone is located directly near the surface. Coagulation of the oxide aerosol in the track of a burning particle leads to aerogelation with the formation of huge aggregates. Analytical expressions for approximate calculation of the parameters of the oxide particles and zones of their formation are proposed.

Key words: particle burning, aluminum, titanium, oxide formation, nanoparticles, spherules, aggregates, morphology, mobility, charge, fractal dimension.
\end{abstract}

\section{INTRODUCTION}

The combustion of single metal particles is of both fundamental [1, 2] and applied [3] interest. In particular, combustion of metal powders in an aerodisperse flame [3] is regarded as a method for synthesizing nanosized oxide particles for the manufacture of semiconductor ceramic catalytic materials. At the same time, it is known that aluminum, magnesium, titanium, beryllium, and zirconium can be added as energetic ingredients to solid propellants, explosives, and pyrotechnic formulations $[2,4,5]$. The combustion of a single metal particle in air at atmospheric pressure is often treated as a simple physical model for the processes involved

\footnotetext{
${ }^{1}$ Institute of Chemical Kinetics and Combustion, Siberian Division, Russian Academy of Sciences, Novosibirsk 630090; karasev@ns.kinetics.nsc.ru.

${ }^{2}$ Institute of Environmental Engineering,

National Chiao Tung University,

Hsinchu 300, Taiwan.
}

in particle combustion in energetic formulations or in technical devices. Therefore, the combustion of single particles under controlled conditions has been extensively studied theoretically and experimentally $[1,6-8]$. A feature of the metal particle combustion mechanism is the formation of condensed oxide, originally in the form of nanosized particles. During the subsequent evolution, the nanosized particles can be transformed to submicron-sized and micron-sized aggregates; their size distribution should be taken into account in calculations of many processes in technical devices. However, because of a lack of experimental data, an established model for metal combustion that includes the formation of oxide nanoparticles is currently not available.

The aim of the present work was to study the formation mechanism of $\mathrm{TiO}_{2}$ and $\mathrm{Al}_{3} \mathrm{O}_{3}$ nanoparticles during combustion of $\mathrm{Ti}$ and $\mathrm{Al}$ particles in air at atmospheric pressure. Emphasis was on determining the size of primary oxide nanoparticles, the equiva- 
lent sizes, morphology, and electric charge of the aggregates formed from the nanoparticles, and the combustion stages of the metal droplets.

$\mathrm{Al}$ combustion has been studied fairly comprehensively [8]; therefore, the present work dealt primarily with titanium combustion.

\section{EXPERIMENTAL}

Combustion of the metal particles and the formation of the oxide aerosol was studied in two types of experiments. Experiments of the first type were performed with specimens of a pyrotechnic mixture containing metal powders with particle sizes of 4-350 $\mu \mathrm{m}$, ammonium perchlorate as the oxidizer, and hydroxyl terminated polybutadiene (HTPB) as the binder. A specimen was burned at $1 \mathrm{~atm}$ in a 20 liters chamber with air purified from atmospheric aerosol be means of an analytical aerosol filter. The burning time of the specimen was a few seconds. During combustion of the specimen, the burning metal particles were dispersed and their subsequent combustion proceeded in air. The video recorded velocity of motion of the droplets was $0.1-0.5 \mathrm{~m} / \mathrm{sec}$, and the burning time was 20-300 msec. Aerosol samples were occasionally taken from the chamber during $20 \mathrm{~min}$ after the completion of the sample combustion. Sampling was carried out thermophoretically for transmission electron microscopic (TEM) analysis; in addition, an aerosol flux was supplied to an aerosol optical cell similar to the Millikan cell, where the motion of the aggregates (coagulated particles) was recorded by a video camera with a microscope lens and $\mathrm{He}-\mathrm{Ne}$ laser illumination. The light scattered by the aerosol particles at an angle of $90^{\circ}$ passed through the microscope lens, which formed their magnified images on the matrix of the chargedcoupled device (CCD) camera. The dimensions of the field of view in the focal plane were about $0.3 \times 0.4 \mathrm{~mm}$. The spatial resolution of the optical system was $3 \mu \mathrm{m}$, and objects of smaller sizes were recorded as spots. In the cell there were two parallel plate electrodes spaced $0.25 \mathrm{~cm}$ apart, which allowed a homogeneous electric field to be switched on. Video recording of particle motion allowed the determination of the Brownian diffusion coefficient of the aggregates and their sedimentation velocity, and the application of the field made it possible to calculate their charge and dipole moment.

In experiments of the second type, single particles of size $100-350 \mu \mathrm{m}$ were added to a metal-free composition (ammonium perchlorate-organic binder), which was filled in a quartz capillary tube of inner diameter $2.5 \mathrm{~mm}$. During combustion of the composition, the particles were ignited and ejected from the capillary one after another at a velocity of $1-3 \mathrm{~m} / \mathrm{sec}$. The motion of the burning particles was recorded by a high-speed camera. A glass plate was placed on the particle trajectory so that there was a small angle between the particle velocity and the plate surface $-5-17^{\circ}$. The plate was coated with a Formvar film, on which the oxide aerosol from the halo and tail produced by the burning particle was deposited thermophoretically. The deposit was analyzed by optical and transmission electron microscopy. The main advantage of this technique is that the aerosol deposit gives information on the characteristics of oxide particles near the burning particle surface, i.e., in the early stages of particle growth (up to $0.1 \mathrm{msec}$ ). The burning time of the droplet before impact on the plate was varied in a range of 50-150 msec by changing the distance from the capillary to the plate.

\section{RESULTS}

\section{Sizes and Morphology of the Aggregates Produced by Combustion of the Pyrotechnic Mixture}

The aerosol produced by combustion of the metal in the pyrotechnic mixtures is formed of chain-branching $\mathrm{Al}_{2} \mathrm{O}_{3} / \mathrm{TiO}_{2}$ aggregates of size $0.1-10 \mu \mathrm{m}$ which consist of primary spherical particles (spherules) of diameter 5-150 nm. Typical images of the aggregates are given in Fig. 1. X-ray diffraction analysis shows that the crystal structure of the $\mathrm{TiO}_{2}$ spherules is anatase (60\%) and rutile (40\%) and that of the $\mathrm{Al}_{2} \mathrm{O}_{3}$ spherules is the $\alpha$ - and $\gamma$-phases.

Electron-microscopic images of the aggregates were used to measure their equivalent geometrical radius, which is defined as

$$
R=0.5 \sqrt{L W},
$$

where $L$ is the maximum length of the aggregate and $W$ is the maximum extent in the direction perpendicular to $L$.

The aggregate morphology was described using the concept of the fractal dimension $D_{f}[9]$, which is the exponent in the relation between the aggregate mass $M_{a}$ and the equivalent geometrical radius $R$ :

$$
M_{a} \sim R^{D_{f}} .
$$

The fractal dimension was determined by using two approaches for estimating the aggregate mass. The first approach is based on measuring (in arbitrary units) the integral optical density of a TEM image of the aggregate, which is defined as the sum of the gray values (in the range of $0-255$ ) for all pixels of the aggregate. 

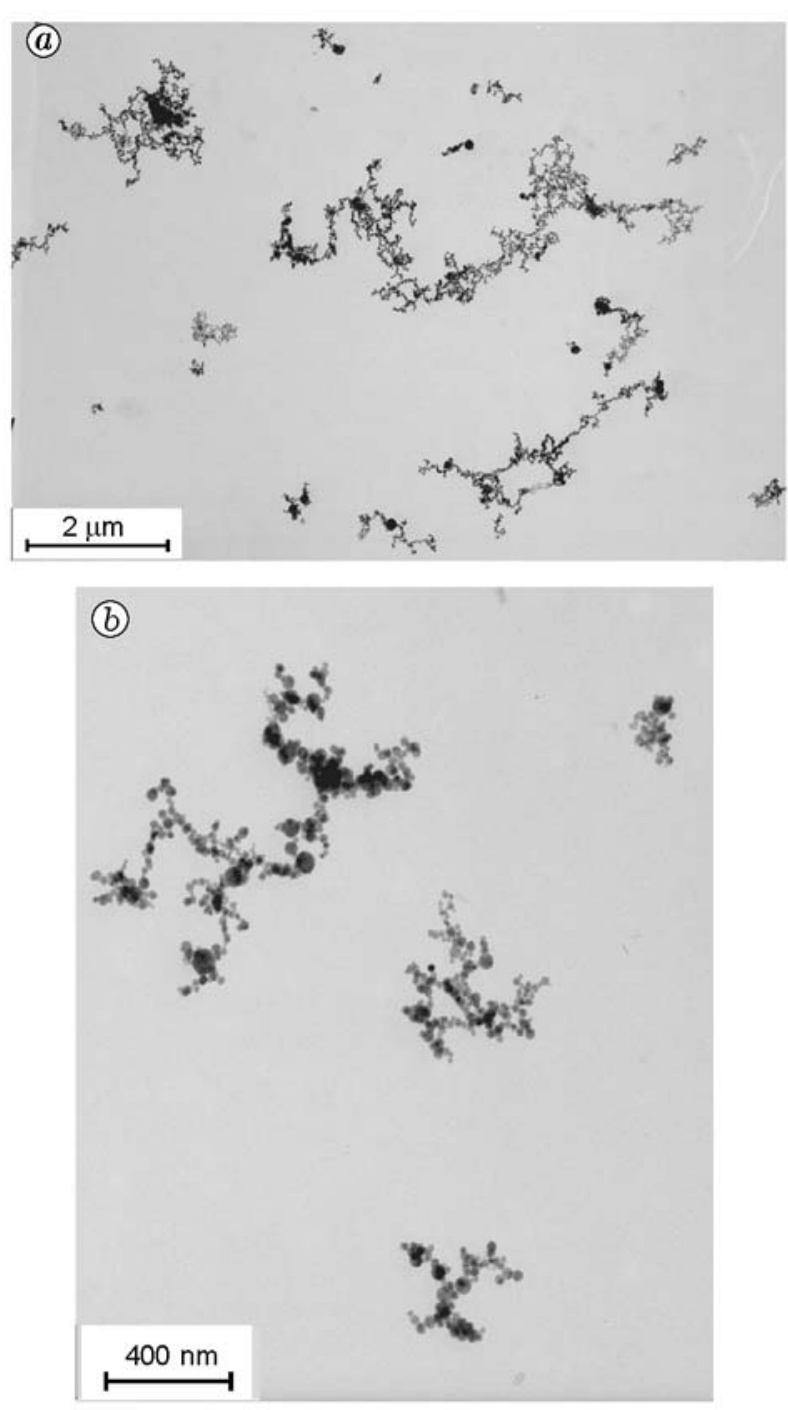

Fig. 1. $\mathrm{TiO}_{2}$ (a) and $\mathrm{Al}_{2} \mathrm{O}_{3}$ (b) aggregates sampled from the reaction vessel in $1 \mathrm{~min}$ after combustion of the pyrotechnic mixture.

It is assumed that the optical density of the image is proportional to the local thickness of the aggregate and the mass is proportional to density. A correction was made for the thickness of the Formvar plate. This method of determining the mass was validated by analytical studies [9], where it was shown that the fractal dimension of a two-dimensional projection of an object is equivalent to the fractal dimension of the three-dimensional object if $D_{f}<2$. In the second approach, the diameters of all spherules in the aggregate were measured and the aggregate mass was calculated by multiplying the total volume of the spherules by the density of $\mathrm{Al}_{2} \mathrm{O}_{3} / \mathrm{TiO}_{2}$. Both approaches give close values of $D_{f}$. For $\mathrm{TiO}_{2}$ aggregates, $D_{f}=1.55 \pm 0.1$ (Fig. 2). In the case of $\mathrm{Al}_{2} \mathrm{O}_{3}$

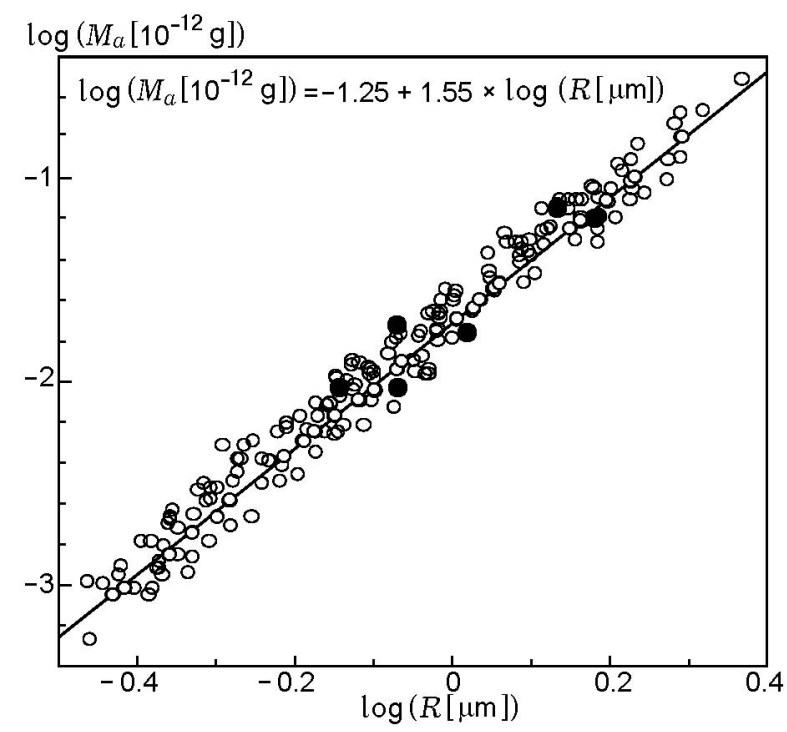

Fig. 2. Mass versus geometrical radius for $\mathrm{TiO}_{2}$ aggregates: points - indicate that the mass determined by summation of the masses of the primary nanoparticles in the aggregate (from TEM images) and points $\circ$ indicate that the mass was found by measuring the integral optical density of images of individual aggregates.

aggregates, $D_{f}=1.6 \pm 0.1$ for particles of size 10, 110, and $340 \mu \mathrm{m}$ and $D_{f}=1.8 \pm 0.1$ for particles of size of $4 \mu \mathrm{m}$. In addition, it turned out that in both cases $\left(\mathrm{Al}_{2} \mathrm{O}_{3}\right.$ and $\left.\mathrm{TiO}_{2}\right)$, the fractal dimension did not depend on the coagulation time (i.e., the time interval between the sample combustion and sampling) in the examined range of $1-20 \mathrm{~min}$.

The mobility radius $\left(R_{m}\right)$ for $\mathrm{TiO}_{2}$ aggregates was determined as a function of the equivalent geometrical radius [Eq. (1)] using the approach described in [10]. In addition, by processing of TEM negatives, we determined the quantitative ratios between the characteristic sizes (radii): the equivalent geometrical radius $(R)$, gyration radius $\left(R_{g}\right)$, and projection-averaged radius $\left(R_{s}\right)$. As a result, we obtained the useful ratio $R: R_{g}: R_{s}: R_{m}=6: 4.5: 2: 1$ (Fig. 3 ). The procedures used to determine the equivalent radii are given below.

The mobility radius $R_{m}$ was determined from records of the Brownian diffusion of aggregates using the following procedure [10]. The diffusion coefficient $D$ was first calculated by the Einstein equation

$$
\overline{(\Delta x)^{2}}=2 D \tau,
$$

where $\overline{(\Delta x)^{2}}$ is the average value of the squared displacement of the aggregate on the axis $x$ for identical time periods $\tau$. Then, $R_{m}$ was calculated from the following equation linking $R_{m}$ to the diffusion coefficient: 


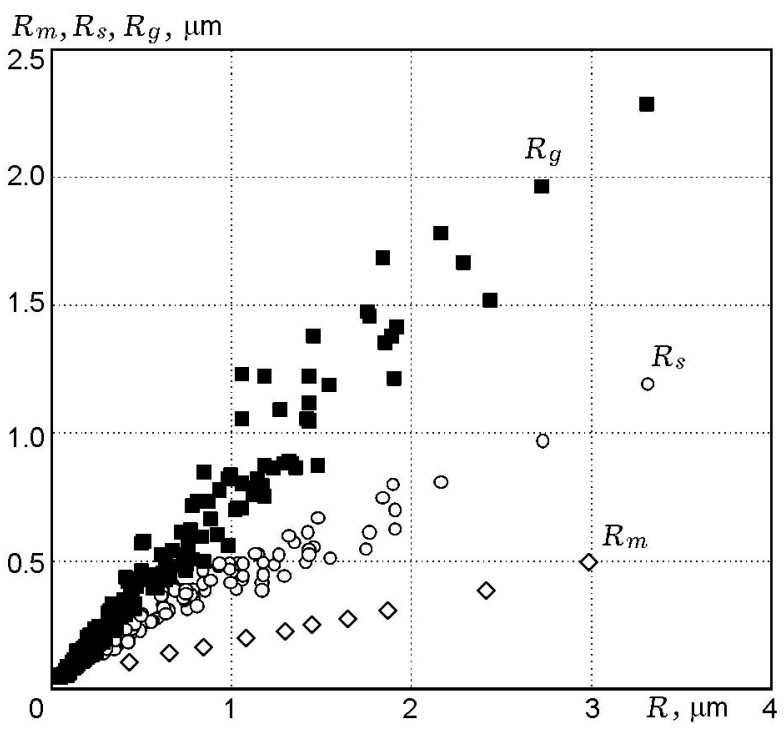

Fig. 3. Brownian mobility radius, projection-averaged radius, and gyration radius versus geometrical radius for $\mathrm{TiO}_{2}$ aggregates.

$$
D=\frac{k T C_{C}}{6 \pi R_{m} \eta},
$$

where $k$ is the Boltzmann constant, $T$ is the temperature, $\eta$ is the viscosity of air, $\lambda$ is the free path of the gas molecules, and $C_{C}=1+\lambda A / R_{m}$ is a correction factor ( $A=1.257)[11]$.

By the definition, the gyration radius $R_{g}$ is the mean-square-root distance of the points of the fractal from the center of mass. In this case, $R_{g}$ was calculated by biniarized (black-and-white) TEM images of the aggregates as follows:

$$
R_{g}=B \sqrt{\frac{1}{\Pi} \sum_{i=1}^{\Pi} r_{0 i}^{2}} .
$$

Here $B$ is the image scale $[\mu \mathrm{m} /$ pixel], $i$ is the pixel number in the aggregate image, $\Pi$ is the total number of pixels in the aggregate image, and $r_{0 i}$ is the distance of the $i$ th pixel from the center of mass. The coordinates of the center of mass are calculated as the mean arithmetic values of the abscissa and ordinate of all pixels of the image of the aggregate.

The projection-averaged radius $R_{s}$ is the radius of a circle with an area equal to the aggregate area. The aggregate area is numerically equal to the number of pixels, so that

$$
R_{s}=B \sqrt{l^{2} \Pi / \pi}
$$

where $l^{2}$ is the pixel area $\left[\right.$ pixel $\left.^{2}\right]$.

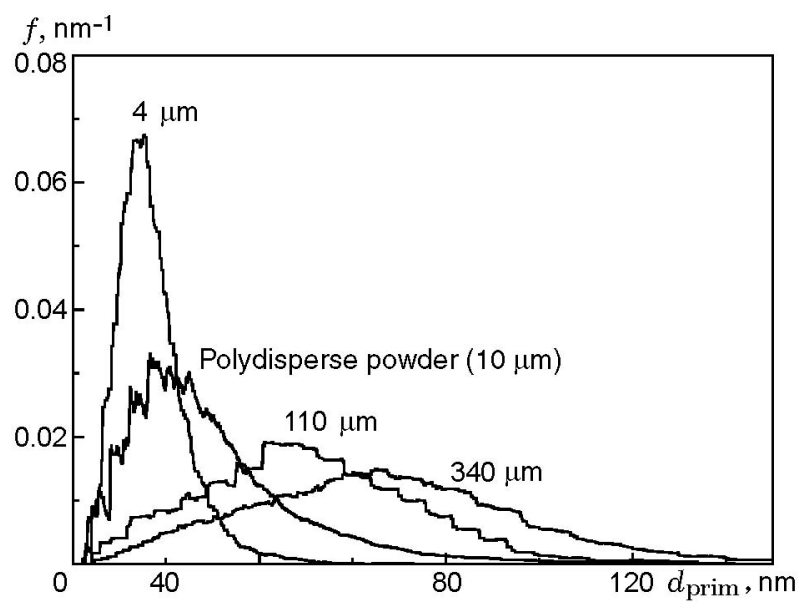

Fig. 4. Size distribution of $\mathrm{Al}_{2} \mathrm{O}_{3}$ primary particles produced by combustion of pyrotechnic mixtures containing a monodisperse $\mathrm{Al}$ powder with particle sizes of 4,110 , and $340 \mu \mathrm{m}$ and a polydisperse powder with a mean particle diameter of $10 \mu \mathrm{m}$.

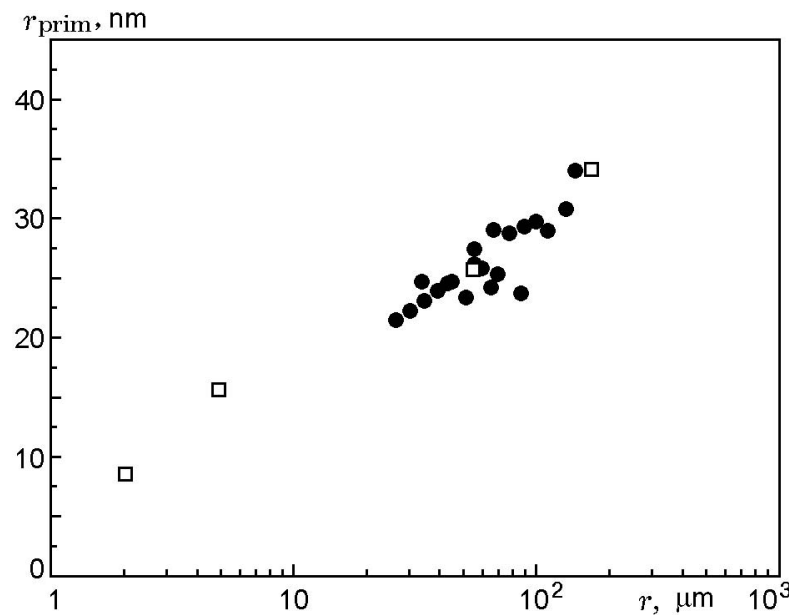

Fig. 5. Mean radius of primary particles versus radius of initial $\mathrm{Al}$ particles in the pyrotechnic mixture: points $\square$ refer to experimental data and points $\bullet$ refer to calculations using the analytical model [see Eq. (26)] and the data of Fig. 9.

\section{Spherule Sizes}

In the investigation of the combustion of individual $\mathrm{Al}$ particles, it was found that the size distribution of $\mathrm{Al}_{2} \mathrm{O}_{3}$ spherules is a function of the diameter of the burning metal droplet. Four series of experiments of the first type were conducted with samples generating burning particles with a known size distribution, namely: monodisperse particles with $d_{10}=340 \mu \mathrm{m}$ and $K_{\text {var }}=0.11$, monodisperse particles with $d_{10}=110 \mu \mathrm{m}$ and $K_{\mathrm{var}}=0.14$, polydisperse particles with an effective size $10 \mu \mathrm{m}$ and $K_{\mathrm{var}}=0.54$, and particles with 


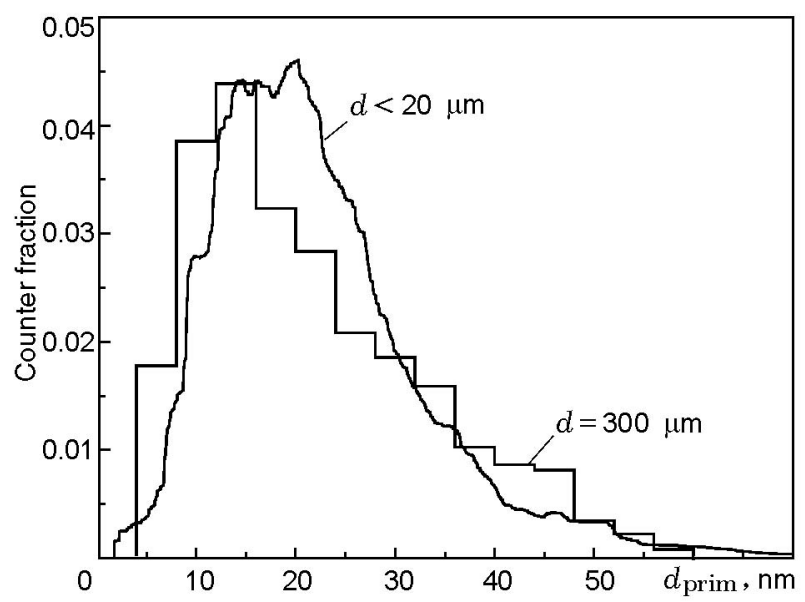

Fig. 6. Size distribution of $\mathrm{TiO}_{2}$ primary particles in the aggregates produced by combustion of single $\mathrm{Ti}$ particles of diameter $d=300 \mu \mathrm{m}$ (spherule sizes are $d_{10}=22.4 \mathrm{~nm}$ and $d_{30}=27.9 \mathrm{~nm}$ ) and a pyrotechnic mixture with particle sizes $d<20 \mu \mathrm{m}$ (spherule sizes are $d_{10}=22.7 \mathrm{~nm}$ and $\left.d_{30}=28.3 \mathrm{~nm}\right)$.

a narrow size distribution with $d_{10}=4.0 \mu \mathrm{m}$ and $K_{\mathrm{var}}=0.23$. Here $K_{\mathrm{var}}=\sigma / d_{10}$ is the coefficient of variation $\left(\sigma=\sqrt{d_{20}^{2}-d_{10}^{2}}\right.$ is the standard deviation). The size distribution of primary $\mathrm{Al}_{2} \mathrm{O}_{3}$ particles (Fig. 4) and the dependence of the mean particle radius of primary spherules $r_{\text {prim }}$ on the radius $r=d_{10} / 2$ of the burning $\mathrm{Al}$ particle (Fig. 5) were obtained.

In the case of $\mathrm{Ti}$ particle combustion, a correlation between the diameter of $\mathrm{TiO}_{2}$ spherules and the size of the initial Ti particles was not found. Figure 6 gives spherule size distributions for combustion of monodisperse single titanium droplets with a size of $300 \mu \mathrm{m}$ (experiments of the first type) and titanium particles with sizes less than $20 \mu \mathrm{m}$ in the pyrotechnic mixture (experiments of the second type). It is evident that the distribution functions are similar and the mean sizes of the primary oxide spherules are close.

\section{Charge Distribution on $\mathrm{TiO}_{2}$ Aggregates}

Using videomicroscopic records of the velocity of aggregate movement in a homogeneous electrical field of strength $200 \mathrm{~V} / \mathrm{cm}$, we calculated the charge of the aggregates by the balance equation between the electrostatic-interaction and viscous-friction forces:

$$
n_{\mathrm{ch}} e E=\frac{6 \pi v \eta R_{m}}{1+\lambda A / R_{m}}
$$

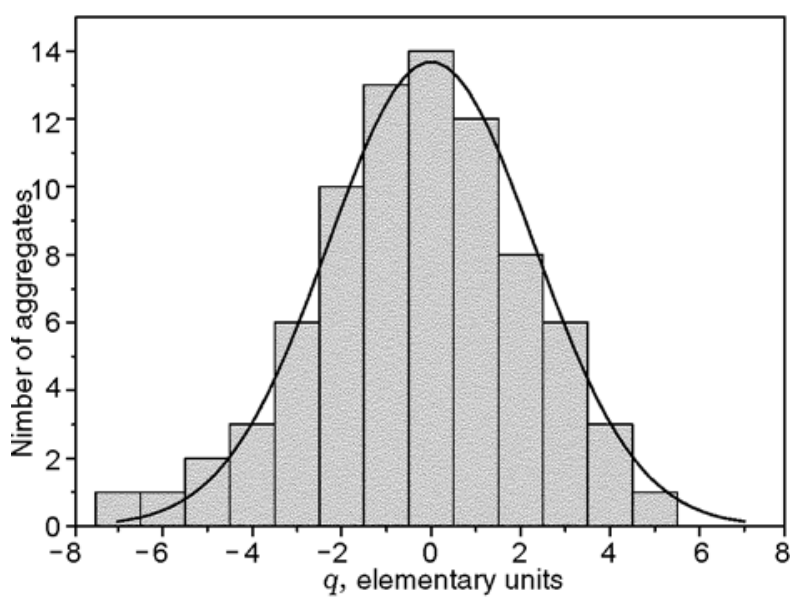

Fig. 7. Charge distribution of $\mathrm{TiO}_{2}$ aggregates having mobility radius $R_{m} \approx 0.18 \mu \mathrm{m}$ : the solid curve is the approximation by the Gaussian distribution $f(q)$.

Here $n_{\mathrm{ch}}$ is the number of elementary charges on the aggregate, $e$ is the value of the elementary charge, $E$ is the electric field strength, and $v$ is the velocity component of the aggregate that arises when the field is switched on. Initially (similarly to [10]), the motion of the aggregate in the absence of the field was recorded and the mobility radius $R_{m}$ was determined; then, the field was switched on and the velocity $v$ was determined. As a result, several Gaussian charge distributions

$$
f(q)=\frac{1}{\sum} \exp \left(-\frac{q^{2}}{2 R_{E} k T}\right)
$$

were plotted for aggregates with quasimonodisperse mobility radii [12]. Here

$$
\sum=\sum_{-\infty}^{\infty} \exp \left(-\frac{q^{2}}{2 R_{E} k T}\right)
$$

( $q$ is the electric charge and $R_{E}=0.31 \mu \mathrm{m}$ is the equivalent charge radius). Figure 7 shows one of the distributions for the mobility radius in a range of $0.15-0.20 \mu \mathrm{m}$. A more detailed discussion of the properties of these distributions is given in [12].

Data on the charge distribution on the $\mathrm{Al}_{2} \mathrm{O}_{3}$ aggregates are presented in [8].

\section{Videorecording of $\mathrm{Al}$ and Ti Droplet Combustion in Air}

Figure 8 shows typical images of a burning aluminum droplet. Characteristic features of aluminum particle combustion are the presence of a lens-like oxide cap on the surface and a reaction zone (halo) distant from the surface, where aluminum oxide nanoparticles 

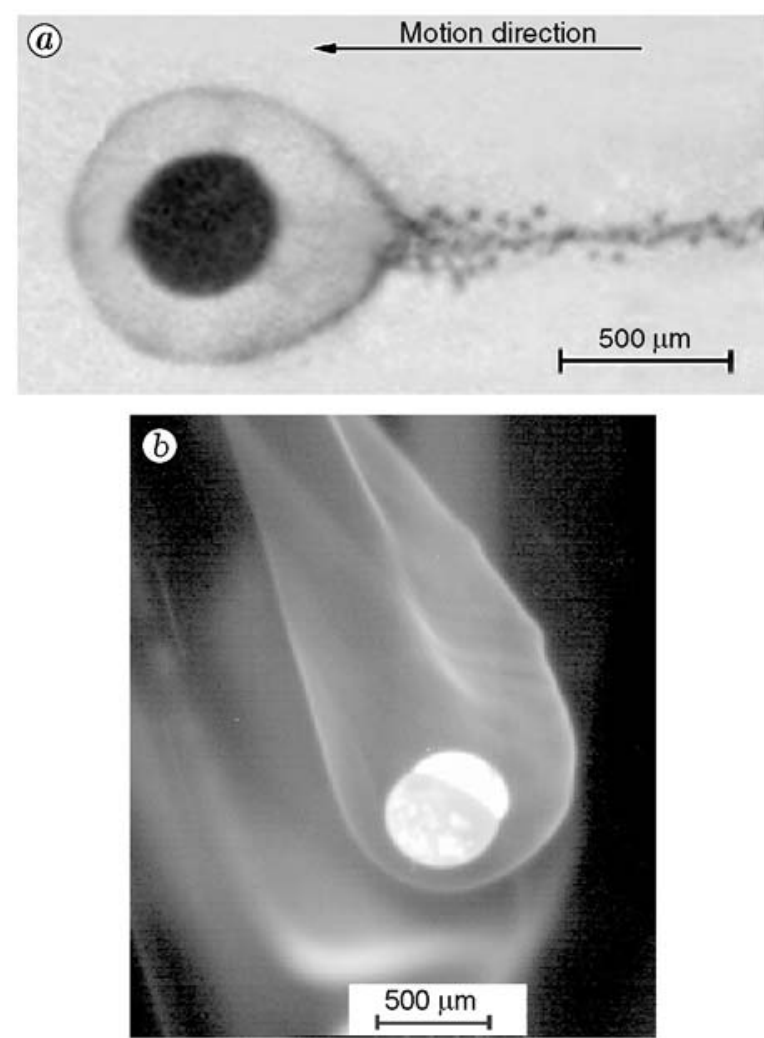

Fig. 8. Burning Al droplet: shadow image behind a blue light filter (a) and in the natural glow (b).

are formed by the reaction between metal vapor and air oxygen. The radius of the reaction zone $R_{\text {reac }}$ (halo) depends on the radius of the burning droplet $r$ (Fig. 9). The burning time of an $\mathrm{Al}$ droplet of diameter of about $100 \mu \mathrm{m}$ in air is $20-30 \mathrm{msec}$. At the end of combustion, the flame is usually extinguished in 1-3 msec. Approximately $1 \%$ of the total number of aluminum particles explode at the end of combustion.

In contrast to $\mathrm{Al}$ particles, almost all $\mathrm{Ti}$ particles exploded, the series of frames in Fig. 10 illustrates this process. The light segment (track) in the first frame $(\tau=0)$ is the particle trajectory for a time of $0.9 \mathrm{msec}$. The next frame $(\tau=1 \mathrm{msec})$ shows the moment of particle explosion. It is evident that in $\tau=1-3 \mathrm{msec}$, most of the resulting fragments explode again. In some cases, a series of explosions is observed. Thus, fragment 3, which exploded in the last frame $(\tau=15 \mathrm{msec})$ resulted from the explosion of fragment 2 .

Figure 11 shows a burning Ti droplet with an oxide smoke halo. We note that, unlike in $\mathrm{Al}$ particle combustion, a reaction zone distant from the surface is not observed, i.e., the zone of oxide nanoparticle formation is in immediate proximity to the droplet surface.

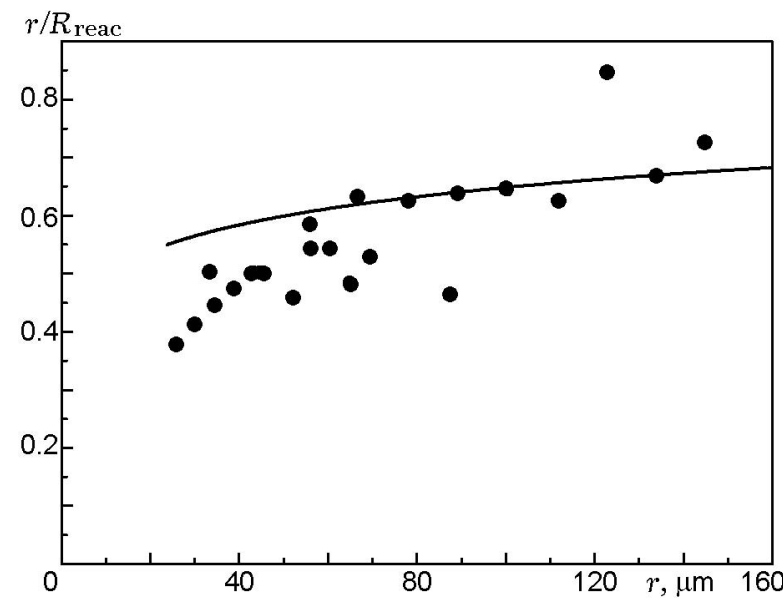

Fig. 9. Ratio of the radius $r$ of a burning $\mathrm{Al}$ particle to the halo radius $R_{\text {reac }}$ as a function of the Al particle radius (points) [17]; the solid curve is a solution of Eqs. (18) and (19).

To obtain data on the early stages of oxide nanoparticle formation, we used "imprints" of the halo and tail zone of the burning metal droplets under their smallangle impact on the plate. Figures 12 and 13 show thermophoretic deposits of $\mathrm{Al}_{2} \mathrm{O}_{3}$ and $\mathrm{TiO}_{2}$ produced by impact of $\mathrm{Al}$ and $\mathrm{Ti}$ droplets and the corresponding optical density profiles of these deposits. In the case of aluminum, the density profile has two maxima, which indicates that the reaction zone is at a distance from the particle surface (see also Fig. 8). In the case of titanium droplet combustion, unlike in the case of aluminum, the deposit density declines monotonically with distance from the center. A TEM image of the $\mathrm{TiO}_{2}$ deposit is shown in Fig. 14. It is evident that single particles and fairly small aggregates are present near the surface and long chain aggregates are observed in the tail zone.

The results demonstrate that there are significant differences between the $\mathrm{Ti}$ and $\mathrm{Al}$ combustion mechanisms.

\section{DISCUSSION OF THE RESULTS}

\section{Dimension of the Halo (Location of the Reaction Zone) for Al Combustion}

The temperature of the burning $\mathrm{Al}$ droplet is equal to the boiling point of aluminum and is $T_{s} \approx 2500 \mathrm{~K}$ [13]. The reaction-zone temperature is limited by the dissociation temperature of $\mathrm{Al}_{2} \mathrm{O}_{3}$; we assume that $T_{\text {reac }} \approx 3200 \mathrm{~K}$ [14]. The diffusion flow of aluminum 

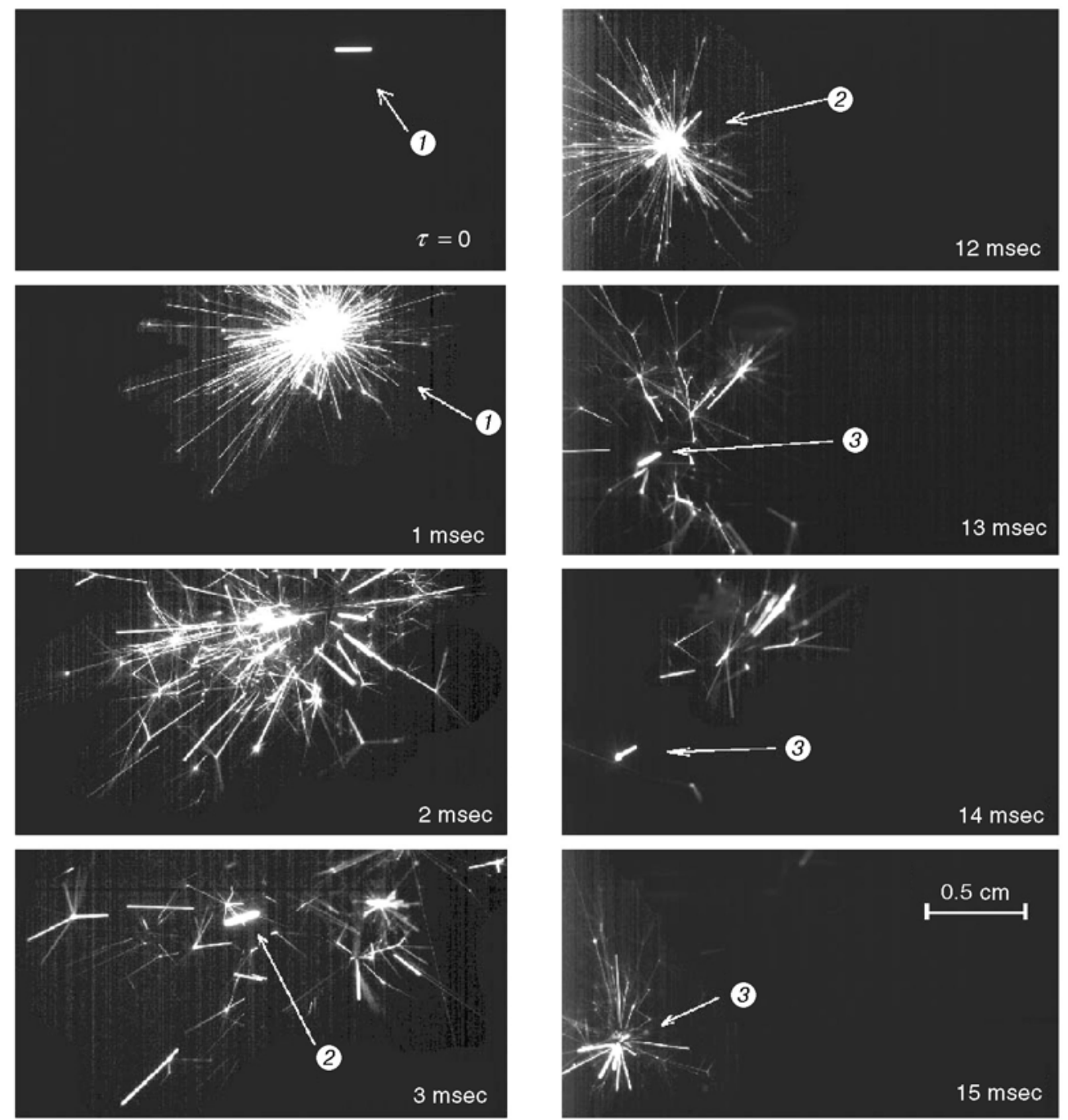

Fig. 10. Sequence of frames illustrating explosion at the end of titanium droplet combustion: the initial diameter of the droplet is $200 \mu \mathrm{m}$; the frame exposure time is $0.9 \mathrm{msec}$; the initial time for each frame is shown in each frame; the exploding fragments are marked by 1-3.

vapor moving from the surface and the oxygen flow moving counter to it interact in the reaction zone to form gaseous $\mathrm{AlO}, \mathrm{Al}_{2} \mathrm{O}, \mathrm{AlO}_{2}$, and $\mathrm{Al}_{2} \mathrm{O}_{2}$ suboxides, which produce liquid $\mathrm{Al}_{2} \mathrm{O}_{3}$ nanoparticles as a result of chemical condensation [14].

The position of the reaction zone relative to the surface can be estimated approximately by solving the stationary diffusion equations for $\mathrm{Al}$ and $\mathrm{O}_{2}$ vapor:

$$
\begin{gathered}
I_{\mathrm{Al}}=-4 \pi \rho^{2} \frac{d C_{\mathrm{Al}}}{d \rho} D_{\mathrm{Al}}, \\
I_{\mathrm{O}_{2}}=-4 \pi \rho^{2} \frac{d C_{\mathrm{O}_{2}}}{d \rho} D_{\mathrm{O}_{2}} .
\end{gathered}
$$

Here $I_{\mathrm{O}_{2}}$ and $I_{\mathrm{Al}}$ are the oxygen and aluminum diffu- sion fluxes, $C_{\mathrm{O}_{2}}$ and $C_{\mathrm{Al}}$ are the oxygen and aluminum concentrations, and $D_{\mathrm{O}_{2}}$ and $D_{\mathrm{Al}}$ are the oxygen and aluminum diffusion coefficients, respectively; $\rho$ is the radial coordinate. The boundary conditions are as follows: $C_{\mathrm{Al}}=C_{\mathrm{Al}}^{0}$ for $\rho=r, C_{\mathrm{Al}}=0$ for $\rho=R_{\mathrm{reac}}, C_{\mathrm{O}_{2}}=C_{\mathrm{O}_{2}}^{\infty}$ for $\rho=\rho^{*}$, and $C_{\mathrm{O}_{2}}=0$ for $\rho=R_{\text {reac }}$. Here $r$ is the Al particle radius, $R_{\text {reac }}$ is the radius of the reaction zone, $C_{\mathrm{Al}}^{0}$ is the aluminum vapor concentration near the surface (for a partial pressure of $1 \mathrm{~atm}$ ), and $C_{\mathrm{O}_{2}}^{\infty}$ is the oxygen concentration at infinity. The value of $\rho^{*}$ will be determined below. It should be noted that the diffusion coefficients in Eqs. (8) and (9) depend on temperature and, hence, on the radial coordinate $\rho$. 


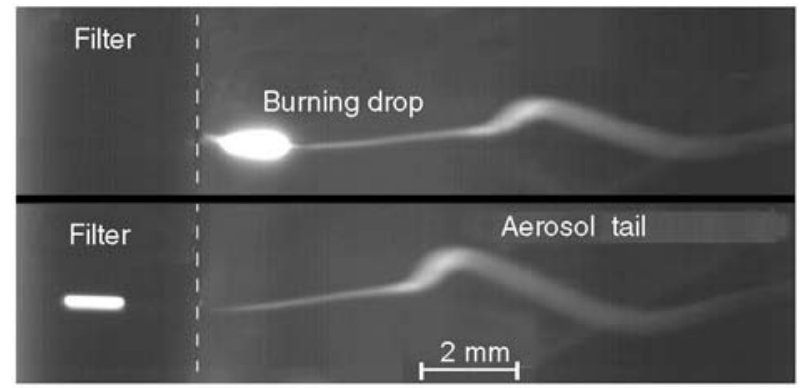

Fig. 11. Two successive frames of a burning titanium droplet in self-radiation, the aerosol tail is in light scattered at an angle of $90^{\circ}$ : the droplet diameter is $200 \mu \mathrm{m}$, the repetition frequency is 1000 frames/sec, the frame exposure time is $0.9 \mathrm{msec}$; the left side of the frame is' shielded by a dense filter in order to partially suppress the natural glow of the burning particle and to record its diameter.
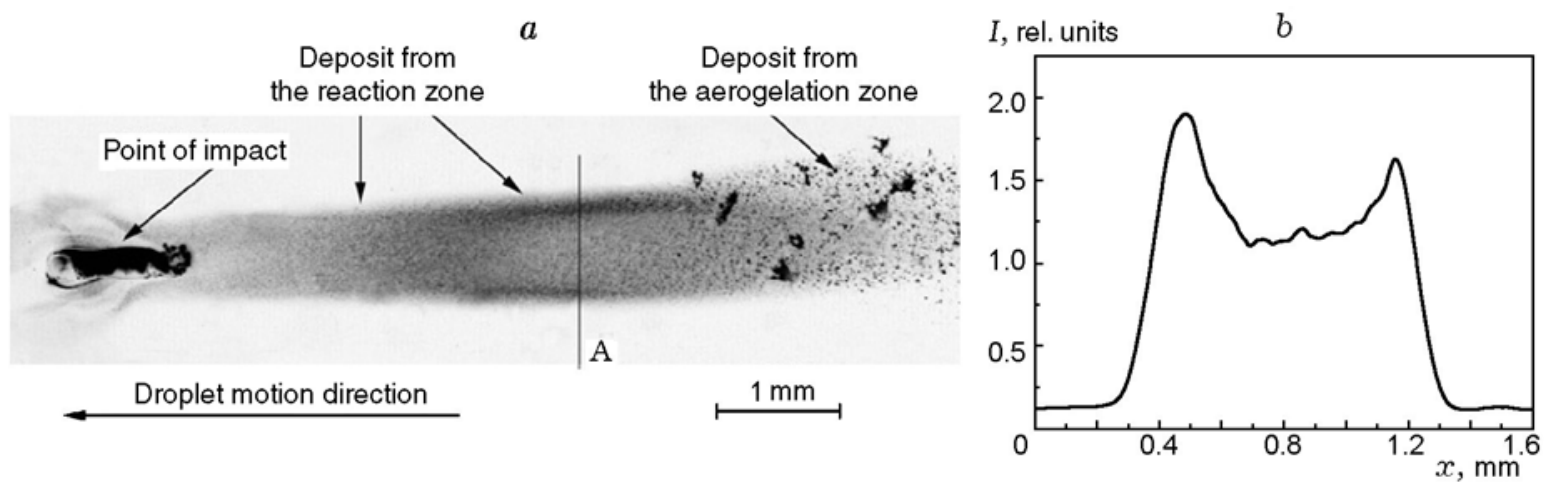

Fig. 12. Deposit from a burning Al particle of initial diameter of $300 \mu \mathrm{m}$ under small-angle impact of the particle on the plate (a) and the density profile of the $\mathrm{Al}_{2} \mathrm{O}_{3}$ deposit in section $\mathrm{A}(\mathrm{b})$.
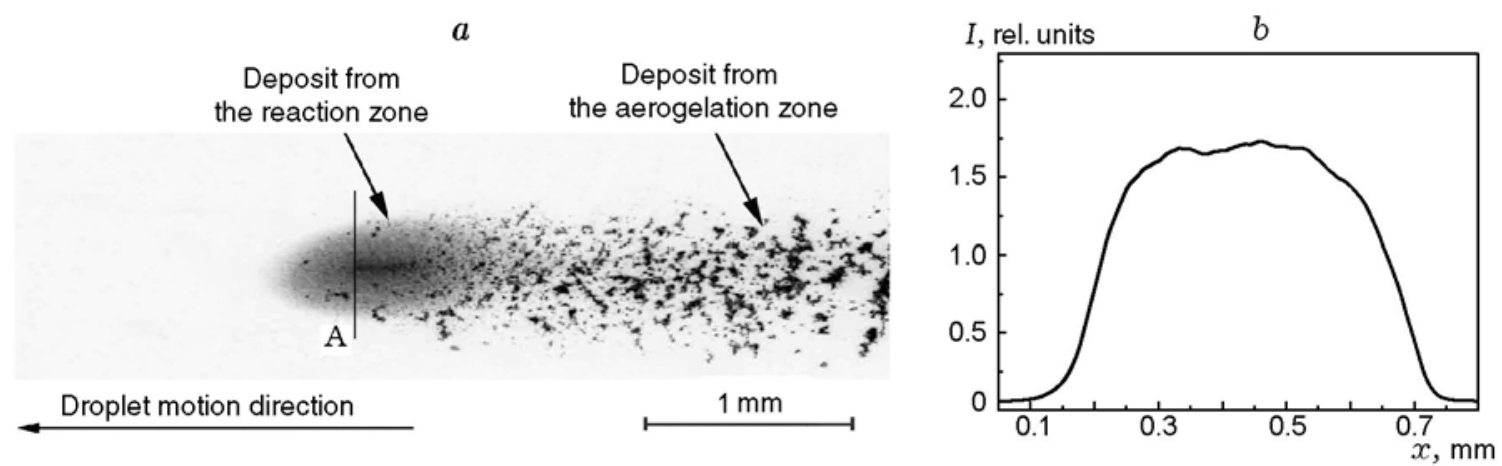

Fig. 13. Deposit from a burning Ti particle of initial diameter $300 \mu \mathrm{m}$ under small-angle impact of the particle on the plate (a) and the density profile of the $\mathrm{TiO}_{2}$ deposit from the reaction zone in section A (b). 
The temperature profile in the neighborhood of the particle can be found from the heat-conductivity equation

$$
q=-4 \pi \rho^{2} \lambda(T) \frac{d T}{d \rho} .
$$

In Eq. (10), $\lambda$ is the thermal conductivity; for air, $\lambda \approx 27 \cdot T^{0.8} \mathrm{erg} /(\mathrm{cm} \cdot \mathrm{sec} \cdot \mathrm{K})[15]$. The boundary conditions for Eq. (10) are as follows: $T=T_{R}$ for $\rho=R_{\text {reac }}$, $T=T_{s}$ for $\rho=r$, and $T=T_{0}$ for $\rho=\rho^{*}\left(T_{0}\right.$ is room temperature). The solution of Eq. (10) is given by

$$
\begin{gathered}
T^{1.8}=T_{s}^{1.8}+\frac{1-r / \rho}{1-r / R_{\text {reac }}}\left[T_{R}^{1.8}-T_{s}^{1.8}\right], \\
r \leqslant \rho \leqslant R_{\text {reac }}, \\
T^{1.8}=T_{s}^{1.8}+\frac{1-R_{\text {reac }} / \rho}{1-R_{\text {reac }} / \rho^{*}}\left[T_{0}^{1.8}-T_{R}^{1.8}\right], \\
R_{\text {reac }} \leqslant \rho \leqslant \rho^{*} .
\end{gathered}
$$

The $\mathrm{O}_{2}$ and $\mathrm{Al}$ diffusion coefficients can be written [15] as

$$
\begin{gathered}
D_{\mathrm{O}_{2}}=D_{\mathrm{O}_{2}}^{0} T^{1.8}, \\
D_{\mathrm{Al}}=D_{\mathrm{Al}}^{0} T^{1.8} .
\end{gathered}
$$

Substituting expressions (11) and (12) into (13) and (14), we solve Eqs. (8) and (9):

$$
\begin{aligned}
I_{\mathrm{Al}}= & \frac{4 \pi D_{\mathrm{Al}}^{0} C_{\mathrm{Al}}^{0}\left[T_{s}^{1.8}-T_{R}^{1.8}\right]}{\left[\frac{1}{r}-\frac{1}{R_{\text {reac }}}\right] \ln \left(\frac{T_{s}^{1.8}}{T_{R}^{1.8}}\right)} \\
I_{\mathrm{O}_{2}}= & \frac{4 \pi D_{\mathrm{O}_{2}}^{0} C_{\mathrm{O}_{2}}^{\infty}\left[T_{R}^{1.8}-T_{0}^{1.8}\right]}{\left[\frac{1}{R_{\text {reac }}}-\frac{1}{\rho^{*}}\right] \ln \left(\frac{T_{R}^{1.8}}{T_{0}^{1.8}}\right)} .
\end{aligned}
$$

The oxygen and aluminum fluxes are linked by the stoichiometric relation

$$
I_{\mathrm{Al}}=\frac{4}{3} I_{\mathrm{O}_{2}} .
$$

The ratio of the diffusion coefficients is [16]

$$
\frac{D_{\mathrm{Al}}}{D_{\mathrm{O}_{2}}}=\sqrt{\frac{\mu_{1}}{\mu_{2}}} \frac{\sigma_{1}}{\sigma_{2}} \approx 1.34 .
$$

Here $\sigma_{1}$ and $\sigma_{2}$ are the collision cross sections between $\mathrm{O}_{2}$ and $\mathrm{N}_{2}$ and between $\mathrm{Al}$ and $\mathrm{N}_{2}$, respectively, and

$$
\mu_{1}=\frac{m_{\mathrm{O}_{2}} m_{\mathrm{N}_{2}}}{m_{\mathrm{O}_{2}}+m_{\mathrm{N}_{2}}}, \quad \mu_{2}=\frac{m_{\mathrm{Al}} m_{\mathrm{N}_{2}}}{m_{\mathrm{Al}}+m_{\mathrm{N}_{2}}},
$$

where $m_{\mathrm{Al}}, m_{\mathrm{O}_{2}}$, and $m_{\mathrm{N}_{2}}$ are the atomic (molar) weights of $\mathrm{Al}, \mathrm{O}_{2}$, and $\mathrm{N}_{2}$, respectively. Taking into account that $C_{\mathrm{Al}}^{0} / C_{\mathrm{O}_{2}}^{\infty} \approx 0.57$, from Eqs. (15)-(17), we obtain

$$
\frac{R_{\text {reac }} / r-1}{1-R_{\text {reac }} / \rho^{*}} \approx 1.92
$$

The quantity $\rho^{*}$ in Eq. (18) corresponds to the distance at which the oxygen concentration can be considered approximately equal to the initial concentration $C_{\mathrm{O}_{2}}^{\infty}$. It can roughly be estimated as

$$
\rho^{*} \approx R_{\text {reac }}+l_{\text {diff }} .
$$

Here $l_{\text {diff }}=\sqrt{2 D_{\mathrm{O}_{2}} \tau_{*}}$ is the characteristic diffusion length, where $D_{\mathrm{O}_{2}} \approx 2.3 \mathrm{~cm}^{2} / \mathrm{sec}$ is the oxygen diffusion coefficient at a certain intermediate temperature, for example $1500 \mathrm{~K}$ and $\tau_{*}=R_{\text {reac }} / v_{\text {gas }}$ is the characteristic time ( $v_{\text {gas }}$ is the incident flow velocity in the reaction zone). Simultaneous solution of Eqs. (18) and (19) yields the ratio $r / R_{\text {reac }}$. The calculation result is shown in Fig. 9 (see the curve). It is evident that there is satisfactory agreement with experimental data (see the points in Fig. 9).

\section{$\mathrm{Al}_{2} \mathrm{O}_{3}$ Spherule Size}

Experimental results [17] have shown that the oxide-spherule diameter depends on the burningparticle size (see Fig. 5). To explain this dependence, we estimate the spherule diameter using a simple model. In Fig. 12b, it is evident that the width of the reaction zone is approximately $0.3 R_{\text {reac }}$. Then, the reaction volume is equal to

$$
V_{\text {reac }}=4 \pi R_{\text {reac }}^{2} \cdot 0.3 R_{\text {reac }} .
$$

In the reaction zone, the oxide vapor supersaturation is very high; therefore, we assume that the initial cluster contains two $\mathrm{Al}$ atoms. Then, with allowance for (15) and (20), the nucleation rate is expressed as

$$
\omega=\frac{I_{\mathrm{Al}}}{2 V_{\text {reac }}}=\frac{D_{\mathrm{Al}} C_{\mathrm{Al}}^{0} \varphi^{3}}{0.4 r^{2}(1-\varphi)},
$$

where $\varphi=r / R_{\text {reac }}$ is the experimentally measured [17] ratio of the radii of the burning droplet and the reaction zone (see Fig. 9). The residence time in the reaction zone can be found using the Stokes equation for the tangential velocity component $v_{t}[18]$ :

$$
v_{t}=-v_{\infty}\left(1-\frac{3}{4} \varphi-\frac{1}{4} \varphi^{3}\right) \sin \theta .
$$

Here $v_{\infty}$ is the gas flow velocity as $\rho \rightarrow \infty$ and $\theta$ is the angular coordinate. The residence time can be set approximately equal to

$$
\begin{aligned}
\tau & \approx \int_{\pi / 6}^{\pi-\pi / 6} \frac{R_{\text {reac }} d \theta}{v_{\infty}\left(1-3 \varphi / 4-\varphi^{3} / 4\right) \sin \theta} \\
& \approx \frac{2.6 r}{v_{\infty} \varphi\left(1-3 \varphi / 4-\varphi^{3} / 4\right)} .
\end{aligned}
$$


The integration limits are chosen from an analysis of the video images. The nanoparticle concentration in the reaction zone $n$ is estimated from the condition that the nucleation and coagulation rates are equal:

$$
K n^{2}=\omega,
$$

where $K$ is the coagulation constant. The mean nanoparticle radius is found from the material balance equation linking the mass of $\mathrm{Al}$ atoms that enter the reaction zone for time $\tau$ and the total mass of nanoparticles in the reaction zone:

$$
\frac{\omega \tau}{n}=\frac{4}{3} \pi r_{\text {part }}^{3} \frac{\rho_{\mathrm{Al}_{2} \mathrm{O}_{3}}}{M} N_{\mathrm{A}} .
$$

Here $r_{\text {part }}$ is the mean radius of nanoparticles in the reaction zone, $\rho_{\mathrm{Al}_{2} \mathrm{O}_{3}} \approx 4 \mathrm{~g} / \mathrm{cm}^{3}$ is the density, $M$ is the molar weight of $\mathrm{Al}_{2} \mathrm{O}_{3}$, and $N_{\mathrm{A}}$ is the Avogadro number. With the use of Eqs. (21), (23), and (25), the mean radius of aluminum oxide nanoparticles in the reaction zone is expressed as

$$
\begin{gathered}
r_{\text {part }}^{3}=\frac{3 M \sqrt{K \omega} \tau}{4 \pi N_{\mathrm{A}} \rho_{\mathrm{Al}_{2} \mathrm{O}_{3}}}=\frac{7.8 M}{4 \pi N_{\mathrm{A}} \rho_{\mathrm{Al}_{2} \mathrm{O}_{3} v_{\infty}}} \\
\times \sqrt{\frac{K D_{\mathrm{Al}} C_{\mathrm{Al}}^{0}}{0.4} \frac{1}{1-3 \varphi / 4-\varphi^{3} / 4} \sqrt{\frac{\varphi}{1-\varphi}} .}
\end{gathered}
$$

The nanoparticles are entrained in the gas flow to form a smoke tail. The temperature decreases rapidly with distance from the burning particle, and at the exit from the reaction zone, it reaches the solidification point of the oxide (see Fig. 8a). Next, coagulation of the solid particles forming the aggregates occur. Therefore, we assume that the spherule size is equal to the nanoparticle size at the exit from the reaction zone.

To estimate $r_{\text {part }}$, we assume that the diffusion coefficient of $\mathrm{Al}$ atoms in nitrogen is given by the relation [16]

$$
D_{\mathrm{Al}}=\frac{3}{8\left(r_{\mathrm{Al}}+r_{\mathrm{N}_{2}}\right)^{2} C_{\mathrm{N}_{2}} \Omega} \sqrt{\frac{R T\left(m_{\mathrm{Al}}+m_{\mathrm{N}_{2}}\right)}{2 \pi m_{\mathrm{Al}} m_{\mathrm{N}_{2}}}},
$$

where $r_{\mathrm{Al}}$ and $r_{\mathrm{N}_{2}}$ are the radii of the $\mathrm{Al}$ atom and $\mathrm{N}_{2}$ molecule, respectively, $R$ is the gas constant, and $\Omega$ is the collision integral. At a temperature of about $3000 \mathrm{~K}$, $\Omega \approx 0.6[16]$ and $D_{\mathrm{Al}} \approx 15 \mathrm{~cm}^{2} / \mathrm{sec}$. For particles of size $5-60 \mathrm{~nm}$, the mean coagulation constant is $K$ $\approx 10^{-7} \mathrm{~cm}^{3} / \mathrm{sec}$ at a temperature of $3000 \mathrm{~K}$ [19]. Taking into account that the velocity of the incident air flow is $v_{\infty} \approx 10 \mathrm{~cm} / \mathrm{sec}$ in order of magnitude and using experimental values of the ratio $r / R_{\text {reac }}$ (see Fig. 9), we can estimate the radius of primary particles as a function of the size of the initial burning droplet. The calculation results are presented in Fig. 5. It is evident that under the assumptions made, the calculation is in good agreement with experimental data.

\section{Explosion of a Burning Titanium Droplet}

The physical picture of titanium droplet combustion is as follows. After ignition, the temperature of the liquid particle increases rapidly due to the reaction with oxygen on the surface, which is accompanied by heat release. Because of oxygen and nitrogen diffusion into the droplet, it is a $\mathrm{Ti}-\mathrm{O}-\mathrm{N}$ liquid solution. The nitrogen concentration in the droplet reaches $10 \%$ (at.) [7], which is not sufficient for the formation of solid-state TiN. In the first 150 msec of combustion, the droplet temperature reaches $2700 \mathrm{~K}$ and then declines to $2200 \mathrm{~K}$, and the process is ended in an explosion [7] (see Fig. 10). The temperature decline in 150 msec after the combustion initiation is probably related to a decrease in the heat-release rate with decreasing rate of oxygen diffusion into the droplet due to a decrease in the oxygen concentration radial gradient. Ultimately, the freezing temperature is reached. By that time, the mean oxygen concentration in the particle is about 40\%(at.) [7]. An increase in the dissolved-oxygen concentration leads to an increase in the phase-transition temperature. For the $\mathrm{Ti}-\mathrm{O}$ system, it is equal to approximately $2100 \mathrm{~K}$. The phase transition involves the formation of two solid phases: $\mathrm{TiO}$ and $\mathrm{Ti}_{2} \mathrm{O}_{3}$. The presence of dissolved nitrogen favors a decrease in the phase-transition temperature by a few tens of degrees, but this will be ignored in the subsequent qualitative estimation. The solid phase probably begins to form on the face part of the moving particle, which should be colder because of the incident air flow, and then, a solid shell forms which covers the entire surface of the liquid core. The formation of the solid shell is accompanied by release of gaseous nitrogen into the interior of the particle. It is assumed that the particle explodes when the excess nitrogen pressure in the shell becomes equal to its ultimate strength.

The ultimate strength of the spherical shell can be estimated as

$$
F_{\mathrm{lim}}=4 \pi \sigma\left[r_{\mathrm{sh}}^{2}-\left(r_{\mathrm{sh}}-\delta\right)^{2}\right],
$$

where $\sigma=40 \mathrm{MPa}$ is the ultimate tensile strength per unit surface, $r_{\mathrm{sh}}$ is the outer radius of the solid shell, and $\delta$ is the thickness of the solid layer (i.e., the difference between the outer radius and the radius of the liquid interior). The average velocity of the fragments $\left(v_{f} \approx\right.$ $360 \mathrm{~cm} / \mathrm{sec})$ and their number $(\approx 100)$ were obtained by analysis of a large number of video images of exploding droplets of diameter $100 \mu \mathrm{m}$. The total kinetic energy of the fragments is $E_{\text {kin }}=m v_{f}^{2} / 2 \approx 0.14 \mathrm{erg}$, where $m$ is the droplet mass. The increase in the surface energy $E_{\text {surf }}$ due to the formation of a new surface of the fragments can be found using the surface tension of titanium oxide $\gamma \approx 270 \mathrm{dyn} / \mathrm{cm}$ [15]. Estimation gives a value $E_{\text {surf }}=0.31 \mathrm{erg}$. The total energy spent in the 
dispersion of the liquid is $E_{\mathrm{tot}}=E_{\mathrm{kin}}+E_{\mathrm{surf}}=0.45 \mathrm{erg}$. This energy is part of the work of the excess pressure, and the other part is spent in the gas expansion resulting from the explosion. The lower bound of the excess pressure can be estimated assuming that the total energy of the scattering fragments $E_{\text {tot }}$ is equal to the work $W_{p}$ due to the excess pressure.

To calculate the excess pressure of dissolved gas in the case of a thin shell, we use the Vant Hoff law

$$
W_{p}=N R T \ln \frac{p_{\text {in }}}{p_{0}} \approx N R T \ln \frac{N R T}{(4 / 3) \pi r^{3} p_{0}} .
$$

Here $p_{\text {in }}$ is the pressure inside the shell, $p_{0}$ is atmospheric pressure, and $N$ is the number of moles of dissolved gas. For $r_{\mathrm{sh}}=5 \cdot 10^{-3} \mathrm{~cm}, W_{p}=0.45 \mathrm{erg}$, and $T=2100 \mathrm{~K}$, we obtain the following solution of Eq. (29): $N=5.1 \cdot 10^{-12}$, which corresponds to a shell pressure $p_{\text {in }}=1.7 \cdot 10^{5} \mathrm{~Pa}$. Equating the values of the excessive pressure and the ultimate strength (28), we obtain the following relation for the shell rupture pressure:

$$
p_{\text {in }}-p_{0}=\left[\frac{1}{\left(1-\delta / r_{\mathrm{sh}}\right)^{2}}-1\right] \sigma .
$$

The solution of Eq. (30) gives a value $\delta \approx 4.4 \cdot 10^{-6} \mathrm{~cm}$. Using this value of $\delta$ and the pressure $p_{\text {in }}$, we obtain the nitrogen concentration in the near-surface layer directly before the explosion $C_{\mathrm{N}} \approx 8 \%$. This value of the concentration $C_{\mathrm{N}}$ estimated as the lower bound agrees with the experimental data of [7], where $C_{\mathrm{N}}=10 \%$ for a titanium droplet of diameter $240 \mu \mathrm{m}$.

\section{Formation of $\mathrm{TiO}_{2}$ Nanoparticles}

The formation of titanium oxide nanoparticles is controlled by oxide vaporization from the burningdroplet surface. The vapor pressure $p$ and temperature decrease with distance from the particle; in this case, the degree of supersaturation $S=p / p_{\text {sat }}$ increases since the saturated-vapor pressure $p_{\text {sat }}$ depends strongly on temperature. At a certain distance from the surface, the supersaturation reaches the critical value and nucleation begins.

Because of the presence of a temperature gradient, the nanoparticles move from the surface under the action of the thermophoretic force. In addition, they are entrained in the incident flow and form a smoke tail (see Fig. 11). As follows from Fig. 13a, the diameter of the smoke halo, i.e., the zone around the burning droplet in which the particles are found by optical and electron microscopy) is $\approx 500 \mu \mathrm{m}$ for an initial droplet diameter of $300 \mu \mathrm{m}$. Therefore, the width of the smoke halo around the particle is about $100 \mu \mathrm{m}$. The residence time of oxide nanoparticles $\tau$ in this zone is determined by both the incident-flow velocity and the thermophoretic velocity; therefore, the width of the zone of nanoparticle formation can be estimated as the product of the thermophoretic velocity $u_{T}$ by the time $\tau$. Estimation of the time $\tau$ by Eq. (23) for $\varphi=0.5$ gives a value $\tau \approx 2 \cdot 10^{-4}$ sec. The thermophoretic velocity is determined as follows [11]:

$$
u_{T}=-0.55 \nu \frac{\nabla T}{T},
$$

where $\nu \approx 3 \mathrm{dyn} \cdot \mathrm{cm}$ is the kinematic viscosity of air at $T=2000 \mathrm{~K}$. To calculate $\nabla T / T$ by Eq. (31), we use the temperature profile in the neighborhood of the particle obtained by solving the heat-conductivity equation (10) subject to the boundary conditions $T=T_{s}$ at $\rho=r$ and $T=T_{0}$ for $\rho \approx 3 \sqrt{2 a \tau} \approx 6 r$, where $a=2.2 \mathrm{~cm}^{2} \cdot \mathrm{sec}$ is the temperature diffusivity of air at $T=1200 \mathrm{~K}$ (an intermediate value between $T_{s}$ and $T_{0}$ ). The solution of Eq. (10) is given by

$$
\begin{gathered}
T^{1.8}(\rho) \approx T_{s}^{1.8}-1.2\left(T_{s}^{1.8}-T_{0}^{1.8}\right)\left[1-\frac{r}{\rho}\right], \\
R \leqslant \rho \leqslant 6 r .
\end{gathered}
$$

This estimation gives $\nabla T / T \approx 30 \mathrm{~cm}^{-1}$ in the zone of nanoparticle formation, and using expression (31), we determine the thermophoresis velocity $u_{T} \approx 50 \mathrm{~cm} / \mathrm{sec}$. As a result, the thermophoretic length is equal to $u_{T} \times \tau \approx 100 \mu \mathrm{m}$, which agrees with the experimentally measured width of the zone nanoparticle formation (zone of the smoke halo).

Let us estimate the rate of generation of titanium oxide vapor $F$. In experiments with videorecording, it was found that the burning time of a Ti droplet of radius $r=150 \mu \mathrm{m}$ to explosion is $t_{\text {burn }} \approx 0.2 \mathrm{sec}$. We assume that during this time, approximately half of the Ti atoms is transferred to vapor, i.e., the coefficient of transition to vapor is $\alpha=0.5$. Then,

$$
F=\alpha \frac{4 \pi r^{3}}{3} \frac{\rho_{\mathrm{Ti}}}{M_{\mathrm{Ti}}} N_{\mathrm{A}} \frac{1}{t_{\text {burn }}} \approx 1.8 \cdot 10^{18} \mathrm{sec}^{-1},
$$

where $\rho_{\mathrm{Ti}}=4.1 \mathrm{~g} / \mathrm{cm}^{3}$ and $M_{\mathrm{Ti}}=47.9 \mathrm{~g}$ are the density and atomic weight of titanium. Assuming that the volume-averaged radius of the spherules is $r_{\text {prim }}$ $=14 \mathrm{~nm}$ (see. Fig. 6), we obtain the particle concentration

$$
\begin{aligned}
n_{\text {part }}= & \alpha\left(\frac{r}{r_{\text {prim }}}\right)^{3} \frac{\rho_{\mathrm{Ti}} M_{\mathrm{TiO}_{2}}}{\rho_{\mathrm{TiO}_{2}} M_{\mathrm{Ti}}} \frac{\tau}{t_{\mathrm{burn}}} \frac{1}{V_{n}} \\
& =1.4 \cdot 10^{13} \mathrm{~cm}^{-3},
\end{aligned}
$$

where $\rho_{\mathrm{TiO}_{2}}=3.8 \mathrm{~g} / \mathrm{cm}^{3}$ is the density of the oxide, $M_{\mathrm{TiO}_{2}}=79.9 \mathrm{~g}$ is its molecular weight, and $V_{n}$ is the 

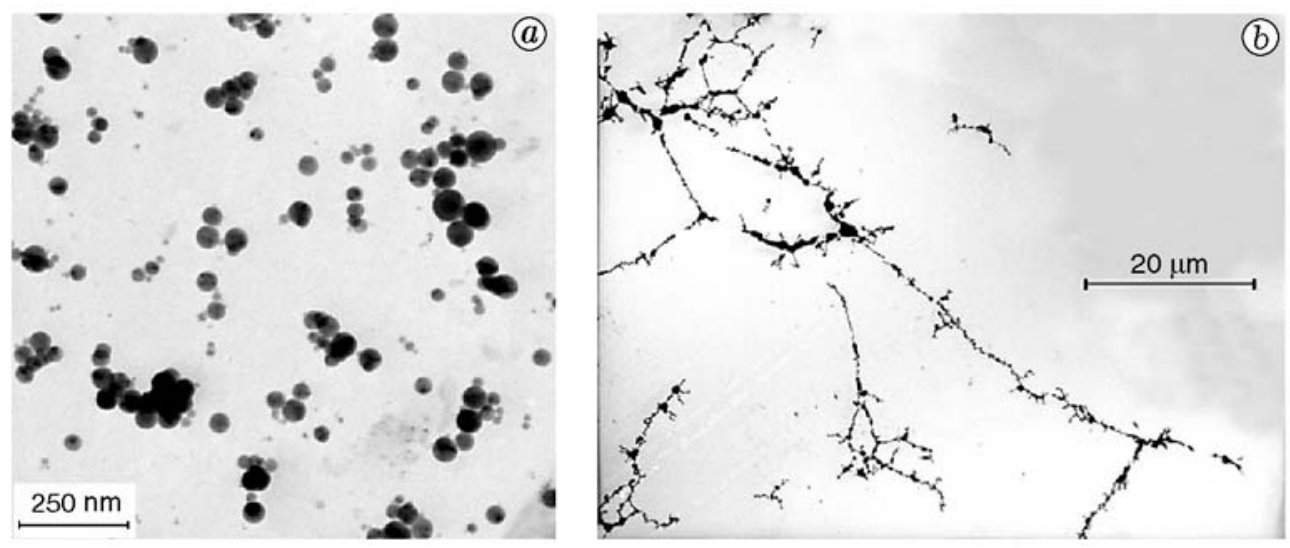

Fig. 14. TEM images of titanium oxide particles from the reaction zone (a) and the aerogelation zone (b).

volume of the zone containing nanoparticles. The critical nucleation rate is $\Phi_{\mathrm{cr}} \approx n_{\mathrm{part}} / \tau \approx 10^{17} \mathrm{~cm}^{-3} \cdot \mathrm{sec}^{-1}$. To estimate the distance from the droplet surface at which nucleation begins, we use the classical nucleation theory taking into account the Reiss factor [20,21]. The nucleation rate is expressed as

$$
\begin{array}{r}
\Phi \approx \frac{p_{\mathrm{sat}} S}{2 k T \pi r_{\mathrm{cr}}} \sqrt{\frac{3 \ln S}{\rho_{\mathrm{TiO}_{2}} \circledast}} \\
\times \exp \left(-\frac{16 \pi m_{\mathrm{TiO}_{2}}^{2}}{3 \rho_{\mathrm{TiO}_{2}}^{2}(\ln S)^{2}}\left(\frac{\gamma}{k T}\right)^{3}\right),
\end{array}
$$

where $æ=6 \cdot 10^{-12} \mathrm{~Pa}^{-1}$ is the isothermal compression coefficient of titanium oxide, $\gamma$ is the surface tension, $r_{\mathrm{cr}}$ is the radius of a critical nucleus (i.e., a nucleus that is in unstable equilibrium with vapor), and $m_{\mathrm{TiO}_{2}}$ is the mass of the $\mathrm{TiO}_{2}$ molecule. The supersaturation $S$ is linked to the critical nucleus radius by the Kelvin equation [20]:

$$
\ln S=\frac{2 \gamma m_{\mathrm{TiO}_{2}}}{k T \rho_{\mathrm{TiO}_{2}} r_{\mathrm{cr}}} .
$$

The temperature dependence of the saturated vapor pressure of titanium oxide is written as [22]

$$
\log p_{\text {sat }}=11.2-27,000 / T
$$

( $p_{\text {sat }}$ is in torr). The titanium oxide vapor pressure is estimated from the stationary diffusion equation

$$
I_{\mathrm{TiO}_{2}}=-4 \pi \rho^{2} \frac{d C_{\mathrm{TiO}_{2}}}{d \rho} D_{\mathrm{TiO}_{2}},
$$

where $C_{\mathrm{TiO}_{2}}$ is the concentration of titanium oxide vapor and $D_{\mathrm{TiO}_{2}}$ is the diffusion coefficient of titanium oxide molecules, which depends on the temperature as $D_{\mathrm{TiO}_{2}} \approx 8.2 \cdot 10^{-6} T^{1.7} \mathrm{~cm}^{2} / \mathrm{sec}$ [the calculation is similar to the calculation for $D_{\mathrm{Al}}$, formula (27)]. With the use of (32), the diffusion coefficients can be represented as a function of the coordinates $\rho$ : $D_{\mathrm{TiO}_{2}} \approx 0.01 / \rho^{1.5} \mathrm{~cm}^{2} / \mathrm{sec}$. Now, integrating Eq. (38) subject to the boundary conditions $C_{\mathrm{TiO}_{2}}=C_{\mathrm{TiO}_{2}}^{0}$ $\left(C_{\mathrm{TiO}_{2}}^{0}\right.$ is the saturated-vapor concentration at the surface) for $\rho=r$ and $C_{\mathrm{TiO}_{2}}=0$ for $\rho \approx 3 \sqrt{2 D_{\mathrm{TiO}_{2}} \tau} \approx 5 r$ $\left(D_{\mathrm{TiO}_{2}} \approx 1.4 \mathrm{~cm}^{2} / \mathrm{sec}\right.$ for $\left.T=1200 \mathrm{~K}\right)$, we have

$$
C_{\mathrm{TiO}_{2}} \approx\left[1.8-0.8 \sqrt{\frac{\rho}{r}}\right] C_{\mathrm{TiO}_{2}}^{0}
$$

or

$$
p_{\mathrm{TiO}_{2}} \approx\left[1.8-0.8 \sqrt{\frac{\rho}{r}}\right] p_{\text {sat }}^{*},
$$

where the quantity $p_{\text {sat }}^{*}$ corresponds to $T=2500 \mathrm{~K}$. The dependence of the supersaturation $S$ on $\rho$ is found from Eqs. (37) and (40) by approximating it by a linear function:

$$
\log S \approx 0.046(\rho-150)
$$

( $\rho$ in $\mu \mathrm{m}$ ). Solution of system (35), (36), (41) yields the coordinate at which the nucleation rate reaches a value $\Phi_{\mathrm{cr}}=10^{17} \mathrm{~cm}^{-3} \cdot \mathrm{sec}^{-1}$. The coordinate is equal to $\approx 165 \mu \mathrm{m}$, and the supersaturation $S_{\mathrm{cr}} \approx 5$. Thus, ignoring the dependence of the surface tension on the critical-nucleus radius, we can conclude that the nucleation process starts at about $15 \mu \mathrm{m}$ from the droplet surface.

The results of video recording (see Fig. 8a) and investigation of the deposit formed during the impact of droplets on the plate (see Figs. 12a, 13a, and 14b) indicate that aerogelation occurs in the smoke tail, i.e., long chain branching aggregates form, whose sizes are comparable with the tail diameter. The reason for this is the high concentration of nanoparticles around the burning droplet (see also [23]). The video records show that the smoke tail is not mixed with ambient air, at least, for $t_{\text {tail }}=0.01 \mathrm{sec}$. If the nanoparticle concentration in the 
zone of formation (halo) is set equal to $10^{13} \mathrm{~cm}^{-3}$ [see Eq. (34)], it can be assumed that after the transfer of nanoparticles by the flow into the tail of the burning droplet, their concentration increases to $10^{14} \mathrm{~cm}^{-3}$ due to cooling of the combustion products to room temperature. Using the value $K \approx 2 \cdot 10^{-9} \mathrm{~cm}^{3} \cdot \mathrm{sec}^{-1}$ [19] as the lower bound of the coagulation rate constant, we estimate the particle concentration in the tail after a coagulation time of $0.01 \mathrm{sec}$ :

$$
n_{\text {tail }} \approx \frac{1}{K t_{\text {tail }}}=5 \cdot 10^{10} \mathrm{~cm}^{-3} \text {. }
$$

As is evident in Fig. 14b, the nanoparticles form long chain branching aggregates with cross section of about 10 spherules, on the average. In the coagulation time $t_{\text {tail }}$, the characteristic length of such chains $l_{\text {aggr }}$ is equal to

$$
l_{\text {aggr }}=\frac{10^{14}}{10 \cdot 5 \cdot 10^{10}} d_{\text {prim }}=4 \mu \mathrm{m} .
$$

On the other hand, the average distance between the aggregates at that moment is equal to

$$
l=\frac{1}{\sqrt[3]{n_{\mathrm{tail}}}} \approx \frac{1}{\sqrt[3]{5 \cdot 10^{10} \mathrm{~cm}^{-3}}} \approx 2.7 \mu \mathrm{m} .
$$

Taking into account that the effective distance of electrostatic interaction (due to the presence of charges on the aggregates) has a value on the order of the aggregate length [8] and that the coagulation constant at high aerosol concentrations is much larger than the Smoluchowski constant [23], it becomes clear that aerogelation certainly occurs by the time $10^{-2}$ sec. Let us estimate the limiting length of the aggregates formed by aerogelation. The diameter of the tail zone (i.e., the aerosol zone behind the burning droplet) is $\approx 100 \mu \mathrm{m}$. Then, the effective volume filled with the aerosol is equal to approximately $V_{\text {coag }} \approx 10^{-6} \mathrm{~cm}^{3}$. In $10^{-2} \mathrm{sec}$, the limiting length of the chain aggregates in this volume is equal to $l_{\max }=\left(V_{\text {coag }} / 10\right) \cdot 5 \cdot 10^{10} \cdot 20 \mathrm{~nm}=100 \mu \mathrm{m}$, which agrees with the length of the aggregates presented in Fig. 14b.

\section{CONCLUSIONS}

The combustion of $\mathrm{Al}$ and $\mathrm{Ti}$ particles of size $4-350 \mu \mathrm{m}$ in air is accompanied by the formation of metal oxide aerosol particles in the form of aggregates with sizes of fractions of a micrometer to a few hundred micrometers consisting of primary spherical particles (spherules) of diameter $5-150 \mathrm{~nm}$. The fractal dimension of the aggregates is $D_{f} \approx 1.6$.

For $\mathrm{TiO}_{2}$ aggregates, the ratio between the equivalent geometrical radius, the gyration radius, the projection-averaged radius, and the mobility radius is as follows: $R / R_{g} / R_{s} / R_{m}=6 / 4.5 / 2 / 1$. The aggregates have bell-shaped charge distributions symmetric about zero, with a characteristic value of the charge of about several elementary units.

For $\mathrm{Al}$ particle combustion, the ratio of the radii of the droplet and the reaction zone (halo) and the radius of the primary particles (spherules) depend on the size of the burning particle. The obtained dependences are explained using a simple diffusion model.

Ti droplet combustion is accompanied by a series of successive explosions. This feature of the Ti combustion mechanism is explained with the use of an approximate model based on the assumption that dissolved nitrogen is released into the internal volume as the crystalline shell forms around the liquid droplet and the shell pressure rises. The model predicts that before explosion, the concentration of dissolved nitrogen in the liquid droplet increases to $\approx 8 \%$ (at.).

During titanium combustion, the metal reacts in a heterogeneous regime and oxide nanoparticles are formed by nucleation of oxide vapor at about $15 \mu \mathrm{m}$ from the surface of a burning $\mathrm{Ti}$ droplet of diameter $300 \mu \mathrm{m}$. In this case, the supersaturation of titanium oxide vapor is $S_{\mathrm{cr}} \approx 5$.

In the smoke tail of burning single particles, $\mathrm{Al}_{2} \mathrm{O}_{3}$ and $\mathrm{TiO}_{2}$ aggregates of length from several tens to several hundreds of micrometers were found. The formation of such aggregates is attributed to aerogelation at a high concentration of the spherules.

This work was supported by the Russian Foundation for Basic Research (Grant Nos. 04-03-33162, 04-03-33163, 05-03-90576-NSC_a, 05-02-08290-OFI_a, NSC_Taiwan-RFBR No. 94WFA0600016_Contract No. RP05E15), INTAS Foundation (Grant No. 03-535203), ASTC (Grant No. 3305), and Integration Project of the SD RAS (Grant No. 78).

\section{REFERENCES}

1. E. L. Dreizin, "Experimental study of aluminum particle flame evolution in normal and micro-gravity," Combust. Flame, 116, 323-333 (1999).

2. E. W. Price and R. K. Sigman, "Combustion of aluminized solid propellants," in: V. Yang, T. B. Brill, and Wu-Zhen Ren (eds.), Progress in Astronautics and Aeronautics, V. 185: Solid Propellant Chemistry, Combustion, and Motor Interior Ballistics, Chapter 2.18, AIAA, Reston (2000), pp. 663-687. 
3. A. N. Zolotko, Ya. I. Vovchuk, N. I. Poletaev, et al., "Synthesis of nanooxides in two-phase laminar flames," Combust., Expl., Shock Waves, 32, No. 3, 262-269 (1996).

4. T. Brzustowski and I. Glassman, "Vapor-phase diffusion flames in the combustion of magnesium and aluminum," in: H. Wolfhard, I. Glassman, and L. Green, Jr. (eds.), Heterogeneous Combustion, Academic Press, New York (1964)

5. E. L. Dreizin, "Phase transitions in metal combustion," Progr. Energ. Combust. Sci., 26, 57-78 (2000).

6. P. Bucher, R. A. Yetter, F. L. Dryer, et al., "Flame structure measurement of single, isolated aluminum particles burning in air," in: 26th Symp. (Int.) on Combustion, The Combustion Inst., Pittsburgh (1996), pp. 1899-1908.

7. I. E. Molodetsky, E. P. Vicenzi, E. L. Dreizin, and C. K. Law, "Phases of titanium combustion in air," Combust. Flame, 112, 522-532 (1998).

8. V. V. Karasev, A. A. Onischuk, O. G. Glotov, et al., "Formation of charged aggregates of $\mathrm{Al}_{2} \mathrm{O}_{3}$ nanoparticles by combustion of aluminum droplets in air," Combust. Flame, 138, 40-54 (2004).

9. S. K. Friedlander, Smoke Powder and Haze, Oxford Univ. Press, New York-Oxford (2000).

10. V. V. Karasev, N. A. Ivanova, A. R. Sadykova, et al., "Formation of charged soot aggregates by combustion and pyrolysis: Charge distribution and photophoresis," J. Aerosol Sci., 35, 363-381 (2004).

11. M. M. R. Williams and S. K. Loyalka, Aerosol Science Theory and Practice, Pergamon Press (1991).

12. S. A. Khromova, V. V. Karasev, A. A. Onischuk, et al., "Formation of nanoparticles of $\mathrm{TiO}_{2}$ and $\mathrm{Al}_{2} \mathrm{O}_{3}$ at combustion of metal droplets," in: G. Roy, S. Frolov, A. Starik (eds.), Nonequilibrium Processes, Vol. 2: Plasma, Aerosols, and Atmospheric Phenomena, Torus Press, Moscow (2005), pp. 225-234.

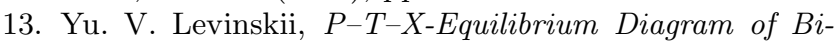
nary Metal Systems: Handbook [in Russian], Metallurgiya, Moscow (1990).
14. P. Bucher, L. Ernst, F. L. Dryer, et al., "Detailed studies on the flame structure of aluminum particle combustion," in: V. Yang, T. B. Brill, Wu-Zhen Ren (eds.), Progress in Astronautics and Aeronautics, Vol. 185: Solid Propellant Chemistry, Combustion, and Motor Interior Ballistics, Chapter 2.19, AIAA, Reston (2000), pp. 689-722.

15. I. S. Grigor'ev and E. Z. Meilikhov (eds.), Physical Quantities: Handbook [in Russian], Énergoatomizdat, Moscow (1991).

16. R. C. Reid, J. M. Prausnitz, and T. K. Sherwood, The Properties of Gases and Liquids, McGraw-Hill, New York (1987).

17. O. G. Glotov, V. E. Zarko, and V. V. Karasev, "Problems and prospects of investigating the formation and evolution of agglomerates by the sampling method," Combust., Expl., Shock Waves, 36, No. 1, 146-156 (2000).

18. L. G. Loitsyanskii, Mechanics of Liquids and Gases, Pergamon Press, Oxford-New York (1966).

19. N. A. Fuchs, The Mechanics of Aerosols, Pergamon, Oxford (1964).

20. P. G. Debenedetti and H. Reiss, "Reversible work of formation of an embryo of a new phase within a uniform macroscopic mother phase," J. Phys. Chem., 108, No. 13, 5498-5505 (1998).

21. A. A. Onischuk, P. A. Purtov, A. M. Baklanov, et al., "Evaluation of surface tension and Tolman length as a function of droplet radius from experimental nucleation rate and supersaturation ratio: Metal vapor homogeneous nucleation," J. Phys. Chem., 124, 014506 (2006).

22. E. K. Kazenas and Yu. V. Tsvetkov, Vaporization of Oxides [in Russian], Nauka, Moscow (1997).

23. C. M. Sorensen, W. B. Hageman, T. J. Rush, et al., "Aerogelation in a flame soot aerosol," Phys. Rev. Lett., 80, 1783-1785 (1998). 